\title{
Sex and Menstrual Cycle Effects on Progressive Ratio Measures of Cocaine Self-Administration in Cynomolgus Monkeys
}

\author{
Nancy K Mello*,', Inge M Knudson' and Jack H Mendelson' \\ 'Alcohol and Drug Abuse Research Center, Harvard Medical School-McLean Hospital, Belmont, MA, USA
}

\begin{abstract}
Fluctuations in ovarian steroid hormones across the menstrual/estrous cycle influence the abuse-related effects of acute cocaine administration in women and chronic cocaine self-administration in rodents, but there have been no comparable studies in non-human primates. The interactions among sex, menstrual cycle phase, and cocaine self-administration $(0.0032,0.01$, and $0.032 \mathrm{mg} / \mathrm{kg} / \mathrm{injection}$ (inj)) under a progressive ratio schedule were investigated in four female and two male cynomolgus monkeys. Females were given unrestricted access to cocaine across 54 menstrual cycles, and males were studied over 23 pseudo-cycles of 30 days duration. Ovulatory cycles were defined by luteal phase elevations in progesterone and 44 cycles were ovulatory. During ovulatory menstrual cycles, females reached significantly higher progressive ratio break points than males at all three unit doses of cocaine $(P<0.00 \mathrm{I})$. During anovulatory cycles, females also reached significantly higher break points than males for $0.032 \mathrm{mg} / \mathrm{kg} / \mathrm{inj}$ cocaine $(P<0.0 \mathrm{I})$. Progressive ratio break points for cocaine $(0.01$ and $0.032 \mathrm{mg} / \mathrm{kg} / \mathrm{inj})$ did not vary significantly as a function of ovarian steroid hormone levels during the follicular and the luteal phase of ovulatory menstrual cycles, or during anovulatory cycles. Progressive ratio break points for $0.0032 \mathrm{mg} / \mathrm{kg} / \mathrm{inj}$ cocaine were significantly higher during the follicular phase than during the late luteal phase $(P<0.05-0.00 \mathrm{I})$. There were no systematic changes in progressive ratio break points in male pseudo-cycles. Significant cocaine dose-related sex differences were observed, but no consistent changes in cocaine self-administration as a function of menstrual cycle phase, or levels of estradiol and progesterone, were detected in female cynomolgus monkeys.

Neuropsychopharmacology (2007) 32, 1956-1966; doi: I0.1038/sj.npp. I 301314; published online 24 January 2007
\end{abstract}

Keywords: menstrual cycle; ovarian steroid hormone; cocaine self-administration; progressive ratio schedule; sex effects

\section{INTRODUCTION}

Cocaine abuse and dependence are major drug abuse problems and the social, medical, and economic costs are almost incalculable (NIDA, 1998; ONDCP, 1998). It is generally agreed that a better understanding of the neurobiological basis of cocaine abuse may facilitate the development of more effective approaches to pharmacotherapy. Cocaine blocks the reuptake of dopamine as well as other monoamines, and there is considerable evidence that dopamine is one of a constellation of neurobiological systems that contribute to cocaine's abuse-related effects (Kuhar et al, 1991; Woolverton and Johnson, 1992; Rothman and Glowa, 1995). Cocaine also has direct effects on the endocrine system (Mello and Mendelson, 1997,

*Correspondence: Dr NK Mello, Alcohol and Drug Abuse Research Center, Harvard Medical School-McLean Hospital, I I5 Mill Street, Belmont, MA 02478, USA, Tel: + I 617855 2746, Fax: + | 617855 2519, E-mail: mello@mclean.harvard.edu

Received 6 July 2006; revised 16 November 2006; accepted 17 November 2006
2002), but the interactions between cocaine's behavioral effects and the hormonal milieu are poorly understood. A number of recent studies in rodents suggest that ovarian steroid hormones may contribute to cocaine's behavioral effects (see for review Lynch et al, 2002; Mello and Mendelson, 2002; Carroll et al, 2004; Festa and QuinonesJenab, 2004). Although the possible mechanisms underlying these effects are unclear, it is known that cocaine stimulates estradiol release in follicular-phase rhesus monkeys (Mello et al, 2000, 2004) and both estradiol and cocaine increase extracellular dopamine levels in rodents (Hemby et al, 1997; Becker, 1999; Becker et al, 2001).

High levels of estradiol at the pro-estrus and estrus phase of the estrous cycle are associated with enhancement of cocaine's reinforcing effects under some conditions in rodents. For example, progressive ratio break points for cocaine were significantly higher at estrus than at other phases of the estrous cycle (Roberts et al, 1989; Hecht et al, 1999). In a cocaine self-administration procedure in which rats could select the dose of cocaine, females selected significantly higher doses of cocaine during estrus than during metestrus/diestrus (Lynch et al, 2000). Estradiol also 
appeared to influence the acquisition of cocaine selfadministration when a relatively low unit dose of cocaine $(0.2 \mathrm{mg} / \mathrm{kg} /$ injection) was available (Lynch et al, 2001). Only $30 \%$ of ovariectomized rats and $50 \%$ of the gonadally intact females given an antiestrogen, Tamoxifen, met the acquisition criteria for cocaine self-administration within 30 days, in contrast to $80 \%$ of gonadally intact controls and $70 \%$ of ovariectomized rats given subcutaneous estradiol (Lynch et al, 2001). However, when drug-naïve ovariectomized rats were given access to higher unit doses of cocaine (1.0-2.5 mg/kg/inj), acquisition of cocaine self-administration did not differ significantly from gonadally intact females (Grimm and See, 1996; Caine et al, 2004) or from ovariectomized females with estrogen replacement (Lynch and Taylor, 2005). Moreover, there were no differences in the shape and position of the cocaine dose-effect curve (0.032-3.2 mg/kg/inj) determined before and after ovariectomy, or in ovariectomized females before and after estradiol replacement (Caine et al, 2004). Ovariectomized females with estrogen replacement self-administered significantly more cocaine than ovariectomized females without estrogen replacement at unit doses of 0.3 and $0.4 \mathrm{mg} / \mathrm{kg} / \mathrm{inj}$, but there were no differences in responding for $0.5 \mathrm{mg} / \mathrm{kg} / \mathrm{inj}$ ( $\mathrm{Hu}$ et al, 2004). Taken together, these results suggest that, although estradiol may enhance the abuse-related effects of cocaine in rats, the unit dose of cocaine available for self-administration is one important determinant of these effects.

The evidence for sex differences in cocaine self-administration is also inconsistent. Females acquired cocaine selfadministration more rapidly than males when a low dose of cocaine $(0.2 \mathrm{mg} / \mathrm{kg} / \mathrm{inj})$ was available in an auto-shaping procedure (Lynch et al, 2000) but not when rats could select the dose of cocaine $(0-2.4 \mathrm{mg} / \mathrm{kg} / \mathrm{inj}$ ) (Lynch et al, 2000). Ovariectomized rats, with and without estradiol replacement, acquired self-administration of a low dose of cocaine $(0.3 \mathrm{mg} / \mathrm{kg} / \mathrm{inj})$ on a fixed ratio (FR) 1 schedule more rapidly than intact or castrated male rats (Hu et al, 2004). Moreover, estradiol administration did not enhance acquisition of cocaine $(0.3-0.5 \mathrm{mg} / \mathrm{kg} / \mathrm{inj})$ in castrated male rats (Jackson et al, 2006) as it usually does in ovariectomized females ( $\mathrm{Hu}$ et al, 2004; Jackson et al, 2006). In contrast, there were no sex differences in days to acquire cocaine $(1.5 \mathrm{mg} / \mathrm{kg} / \mathrm{inj})$ self-administration on an FR 1 schedule or in number of cocaine injections on a progressive ratio schedule (Lynch and Taylor, 2004). When cocaine $(1.0 \mathrm{mg} /$ $\mathrm{kg} / \mathrm{inj}$ ) was available on a FR 5 schedule, after food selfadministration training, female rats met acquisition criteria more slowly than males (Caine et al, 2004). Moreover, there were no significant differences between males and females in the shape or position of the cocaine self-administration dose-effect curves $(0.032-3.2 \mathrm{mg} / \mathrm{kg} / \mathrm{inj})$ (Caine et al, 2004). After 10 days of abstinence, female rats took significantly more cocaine $(1.5 \mathrm{mg} / \mathrm{kg} / \mathrm{inj})$ than males and reached higher progressive ratio break points (Lynch and Taylor, 2004). These findings confirmed and extended an earlier report that female rats reached significantly higher progressive ratio break points for cocaine $(0.5 \mathrm{mg} / \mathrm{ml}$ saline $)$ than males, but when cocaine self-administration was maintained on an FR 1 schedule of reinforcement, there were no sex differences or estrous cycle phase effects (Roberts et al, 1989). When male and female rats were given 1 or $6 \mathrm{~h}$ access to intravenous (i.v.) cocaine $(0.5 \mathrm{mg} / \mathrm{kg} / \mathrm{inj})$ on an FR 1 schedule for 21 days and cocaine dose-effect curves were compared, there were no sex differences in the $1 \mathrm{~h}$ access group, but in the $6 \mathrm{~h}$ access group, females self-administered significantly more cocaine at one dose $(0.25 \mathrm{mg} / \mathrm{kg} /$ inj) than males (Roth and Carroll, 2004).

Clinical studies of the effects of sex and menstrual cycle phase on cocaine's subjective effects also have yielded conflicting findings. Minimal or no significant sex differences (Kosten et al, 1996; Evans et al, 1999; Mendelson et al, 1999b) and greater subjective responses to cocaine (Lukas et al, 1996; Haney et al, 1998; Sofuoglu et al, 1999) and $d$-amphetamine (Munro et al, 2006) in men than in women have been reported. In some studies, the subjective effects of cocaine (Sofuoglu et al, 1999; Evans et al, 2002) and $d$-amphetamine (Justice and de Wit, 1999; White et al, 2002) were greater during the follicular phase than during the luteal phase, and in other studies no menstrual cycle phase differences were detected (Lukas et al, 1996; Mendelson et al, 1999b; Munro et al, 2006). A number of methodological factors, including the route and dose of cocaine administration and differences in rating scales, may have contributed to these inconsistent findings (see for review Terner and de Wit, 2006).

There is compelling evidence that progesterone administered during the follicular phase reduced the positive subjective effects of smoked cocaine (Sofuoglu et al, 2002; Evans and Foltin, 2006) and i.v. cocaine (Sofuoglu et al, 2004). In one study, responses to smoked cocaine $(0,6,12$, or $25 \mathrm{mg}$ ) were compared in the same women during the follicular and the luteal phase of the menstrual cycle, and during the follicular phase of a menstrual cycle when luteal phase levels of oral progesterone were administered (Evans and Foltin, 2006). Progesterone administration during the follicular phase reduced ratings of positive subjective effects in comparison to the follicular phase and the luteal phase of the placebo control cycles (Evans and Foltin, 2006). Men given the same dose of progesterone did not show any differences in subjective responses to cocaine (Evans and Foltin, 2006). In a study of i.v. cocaine $(0.3 \mathrm{mg} / \mathrm{kg})$, progesterone administration attenuated some positive subjective effects in both men and follicular-phase women (Sofuoglu et al, 2004). Recent preclinical studies have also shown that concurrent administration of progesterone and estradiol to ovariectomized female rats blocked the expected estradiolinduced enhancement of acquisition of cocaine $(0.3-0.5 \mathrm{mg}$ / $\mathrm{kg}$ /inj) self-administration on an FR 1 schedule (Jackson et al, 2006). It is well established that progesterone acts as an antagonist of estradiol under several conditions (Dierschke et al, 1973; Wildt et al, 1981; Van Vugt et al, 1992; Clark and Mani, 1994), but the role of estradiol in subjective responses to cocaine and other stimulant drugs remains undetermined. The positive subjective effects of $d$-amphetamine were not greater at the late follicular phase when estradiol levels were high than at the early follicular phase when estradiol levels were low (Justice and de Wit, 2000a). Administration of estradiol to follicular-phase women did not enhance the positive subjective effects of $d$-amphetamine in comparison to placebo (Justice and de Wit, 2000b).

One goal of the present study was to determine if the fluctuations in ovarian steroid hormones that define 
ovulatory menstrual cycles are associated with changes in the reinforcing effects of cocaine in non-human primates. Cynomolgus females were selected for study because the menstrual cycle is very similar to that of women (Hodgen, 1982; Goodman and Hodgen, 1983; Barbier and Belanger, 2003; Appt, 2004). In this drug self-administration model, the interactions between cocaine self-administration and ovarian steroid hormones can be studied in the same females across successive menstrual cycles. A second goal was to compare self-administration of low, moderate, and high unit doses of cocaine in male and female monkeys. Previous studies in rodents have shown that sex differences on a number of behavioral measures of cocaine selfadministration rarely occur when cocaine unit doses are high (Roberts et al, 1989; Lynch et al, 2001; Caine et al, 2004; Lynch and Taylor, 2004). However, when cocaine unit doses are low, behavior is more variable and female rats often acquire cocaine self-administration more rapidly and take more cocaine than males (Lynch et al, 2002; Lynch and Taylor, 2005).

Cocaine self-administration was maintained on a progressive ratio schedule that required a higher ratio of responses for each successive cocaine injection. Progressive ratio schedules are generally agreed to provide a sensitive measure of reinforcing efficacy (Katz, 1990; Roberts et al, 1996; Arnold and Roberts, 1997; Stafford and Branch, 1998; Brebner et al, 2000). It has also been argued that progressive ratio schedules are a better measure of possible hormonal or sex influences on drug selfadministration than low FR schedules because increases in drug response cost decrease the risk for a ceiling effect on drug intake (Lynch et al, 2002; Carroll et al, 2004). In this study, progressive ratio break points for cocaine at the early follicular, mid-follicular, mid-luteal and late luteal phase of normal ovulatory menstrual cycles were studied in female cynomolgus monkeys and compared with progressive ratio break points in male pseudocycles over the same time periods. Ovulatory menstrual cycles were defined by mid-luteal phase elevations in progesterone. This is the first longitudinal study to examine patterns of cocaine self-administration in relation to ovarian steroid hormone levels across successive menstrual cycles in non-human primates and to compare unrestricted cocaine self-administration in male and female cynomolgus monkeys.

\section{METHODS}

\section{Subjects}

Two male (A6809, AP4T) and four female (A5040, A7406, A5438, 016B) cynomolgus monkeys (Macaca fascicularis) were studied as their own control across conditions. Monkeys weighed $4-6 \mathrm{~kg}$ and were maintained on a diet of multiple vitamins, fresh fruit and Lab Diet Jumbo Monkey biscuits (PMI Feeds, Inc., St. Louis, MO), and water was continuously available. A 12-h light-dark cycle was in effect (lights on from 7 am to $7 \mathrm{pm}$ ). Monkeys had been trained to self-administer $1 \mathrm{~g}$ banana-flavored pellets (Precision Primate Pellets Formula L/I Banana Flavor, PJ Noyes Co., Lancaster, $\mathrm{NH}$ ) and patterns of food-maintained responding across the menstrual cycle have been reported previously (Roth et al, 2005). All monkeys were drug-naïve at the beginning of these studies. Three of the females in this study were also subjects in a previous study of the effects of menstrual cycle phase on food-maintained responding (Roth et al, 2005). All females had ovulatory menstrual cycles during that study and were very well adapted to the laboratory environment and blood collection procedures described below.

Animal maintenance and research were conducted in accordance with the guidelines provided by the NIH Committee on Laboratory Animal Resources. The facility was licensed by the United States Department of Agriculture, and protocols were approved by the Institutional Animal Care and Use Committee. The health of the monkeys was periodically monitored by consulting veterinarians. Monkeys had visual, auditory and olfactory contact with other monkeys throughout the study. Operant procedures and foraging and chew toys provided opportunities for environmental manipulation and enrichment. Music or nature videotapes were also played to provide additional environmental enrichment.

\section{Surgical Procedures}

All surgical procedures were performed under aseptic conditions. Monkeys were initially sedated with ketamine $(5-10 \mathrm{mg} / \mathrm{kg})$, and anesthesia was induced with sodium thiopental ( $10 \mathrm{mg} / \mathrm{kg}$, i.v.). Atropine $(0.05 \mathrm{mg} / \mathrm{kg})$ was administered i.m. or s.c. to reduce salivation. Following insertion of an endotracheal tube, anesthesia was maintained with isoflurane ( $1-2 \%$ in oxygen). A single-lumen Silicone rubber catheter (inside diameter 0.028 inch; outside diameter 0.088 inch; Access Technologies, Skokie, IL) was implanted in the internal jugular or femoral vein and exited in the midscapular region. After surgery, monkeys were given the antibiotic Procaine Penicillin G (300 $000 \mathrm{U} / \mathrm{kg} / \mathrm{day}$, i.m.) for 5 days. An analgesic dose of buprenorphine $(0.032 \mathrm{mg} / \mathrm{kg}$, i.m.) was administered twice daily for 3 days. The i.v. catheter was protected by a tether system consisting of a custom-fitted nylon vest connected to a flexible stainless steel cable and fluid swivel (Lomir Biomedical, Malone, NY). This flexible tether system permitted monkeys to move freely. Catheter patency was periodically evaluated by i.v. administration of ketamine $(5 \mathrm{mg} / \mathrm{kg})$ or the shortacting barbiturate methohexital $(3 \mathrm{mg} / \mathrm{kg})$ through the catheter lumen. The catheter was considered to be patent if i.v. administration of ketamine or methohexital produced a loss of muscle tone within $10 \mathrm{~s}$.

\section{Apparatus}

Each monkey was housed individually in a well-ventilated stainless steel chamber $(66 \times 76 \times 94 \mathrm{~cm})$ equipped with a custom-designed operant panel $(28 \times 28 \mathrm{~cm})$ mounted on the front wall. Three square translucent response keys $(6.4 \times 6.4 \mathrm{~cm})$ were arranged $2.54 \mathrm{~cm}$ apart in a horizontal row $3.2 \mathrm{~cm}$ from the top of the operant panel. The center key was transilluminated by a red light when food was available and by a green stimulus light when cocaine was available (Superbright LEDs). Each housing chamber was also equipped with a pellet dispenser (Gerbrands, Model G5210, Arlington, MA) and a syringe pump (Model B5P-1E, 
Braintree Scientific, Braintree, MA; or Model 980210, Harvard Apparatus, South Natick, MA). The syringe pump was used to deliver self-administered cocaine injections or repeated infusions of saline. Monkeys received their morning ration of food, and their health status was evaluated by the technical staff between 0930 and 1030 . The operant panels and data collection were controlled by microprocessors and software purchased from Med Associates Inc. (Georgia, VT).

\section{Operant Schedule Requirements}

Monkeys were trained to respond to banana-flavored food pellets ( $1 \mathrm{~g}$ ) on an FR schedule of reinforcement. Initially, subjects were trained on an FR 1 schedule, and a maximum of 20 food pellets was available during daily $2 \mathrm{~h}$ sessions (1100 to 1300). A $30 \mathrm{~s}$ time out followed the delivery of each pellet, and during this time, the response key was dark and responding had no scheduled consequences. After monkeys obtained the maximum number of food pellets available for 3 consecutive days, the FR value was increased by increments of two responses. If a monkey obtained fewer than 10 reinforcers for three consecutive days, the FR value was decreased by two responses. This progression continued until monkeys obtained the maximum number of available reinforcers under an FR 20 schedule for three consecutive sessions.

After monkeys met this criterion for food-maintained responding, they were placed on a progressive ratio schedule of reinforcement. The progressive ratio schedule consisted of systematic increases in the response requirement necessary to obtain a single food pellet. Each ratio increased by $0.05 \mathrm{log}$ units and the progression of response requirements was as follows: $20,22,25,28,32,36,40,45,50$, $56,63,71,80,89,100,112,126,142,159,178,200,224,252$, 282, 317, 356, 399, 448, 502, $563 \ldots 5632$. This progression was effective in maintaining food and cocaine selfadministration in a previous study (Negus and Mello, 2003). Food self-administration under this progressive ratio schedule was studied for over 10 months in cynomolgus females and over 5 months in cynomolgus males (Roth et al, 2005).

After patterns of food-maintained responding across successive menstrual cycles were examined, monkeys were catheterized as described above and trained to respond for cocaine $(0.032 \mathrm{mg} / \mathrm{kg} / \mathrm{inj})$. Responding for cocaine injections during daily $2 \mathrm{~h}$ sessions was maintained under an FR schedule, and the response requirement was gradually increased from an FR 1 to FR 20. Completion of the ratio requirement resulted in the delivery of cocaine in a volume of $0.1 \mathrm{ml}$ delivered in $1 \mathrm{~s}$, followed by a $30 \mathrm{~s}$ time-out period. Once monkeys earned $\geqslant 20$ cocaine injections for three consecutive days under the FR 20 schedule, cocaine $(0.0032,0.01$, or $0.032 \mathrm{mg} / \mathrm{kg} / \mathrm{inj})$ was available on the same progressive ratio $(\mathrm{PR})$ schedule described above. Cocaine doses were studied in an irregular order and unit doses were changed on day 1 of a menstrual cycle. There was no limit on the number of cocaine injections available to avoid introducing a 'ceiling effect.' Each session lasted until $1 \mathrm{~h}$ had elapsed since a cocaine injection was delivered. Operant sessions were run 7 days a week starting at 1100 .

\section{Menstrual Cycle Phase Monitoring}

Each menstrual cycle was defined by the onset of menstruation, and phases of the menstrual cycle were verified by measuring levels of estradiol and progesterone. Each female monkey was observed every day to determine the onset and duration of menstrual bleeding, and vaginal swabs were also used in some monkeys. Venous blood samples $(2.0 \mathrm{ml})$ for analysis of progesterone and estradiol levels were collected from the femoral vein under light ketamine sedation $(3-5 \mathrm{mg} / \mathrm{kg}$ ) twice each week on Mondays and Thursdays. It is well established that even daily administration of ketamine does not disrupt the menstrual cycle in non-human primates (Channing et al, 1977). Blood samples were collected after completion of the cocaine self-administration session to avoid disrupting operant behavior.

\section{Definition of Menstrual Cycle Phases}

Progressive ratio break points were analyzed for 3 consecutive days at each of four phases of the menstrual cycle: the early follicular phase, the mid-follicular phase, the midluteal phase, and the late luteal phase. The early follicular phase was defined as days 3-5 after the onset of menses on cycle day 1 . The mid-follicular phase was defined as days 8-10 after the onset of menses. The mid-luteal phase for each cycle was defined by the peak progesterone level. The late luteal phase was defined as the last 3 days of the cycle before the onset of the next menstruation. Mid-luteal progesterone levels were used to indicate the presence or absence of ovulation (Mello et al, 1997). In an ovulatory menstrual cycle, progesterone is significantly elevated above baseline for 6-8 days (Mello and Mendelson, 2002) and collection of blood samples every 3 or 4 days is usually sufficient to detect the presence or absence of increases in progesterone levels. Menstrual cycles were classified as ovulatory if peak progesterone levels during the luteal phase were $\geqslant 6 \mathrm{ng} / \mathrm{ml}$ (Mello et al, 1997). In male monkeys, cocaine-maintained responding was analyzed across successive months, and 1 month was equated with one menstrual cycle. Days 3-5, 8-10, 20-22, and 28-30 were selected for analysis to correspond to the hormonally defined phases of the menstrual cycle in females.

\section{Drugs}

Cocaine $\mathrm{HCl}$ was obtained from the National Institute on Drug Abuse (NIH, Bethesda, MD) and dissolved in sterile saline. All cocaine solutions were filter-sterilized using a $0.22 \mu \mathrm{m}$ Millipore filter and stored in pyrogen-free vials. Doses were calculated using the salt form of cocaine.

\section{Plasma Hormone Analyses}

Data are reported for the analysis of estradiol and progesterone in plasma. Plasma concentration of $17 \beta$-estradiol $\left(\mathrm{E}_{2}\right)$ was determined in duplicate using a direct, doubleantibody radioimmunoassay (RIA) (MP Biomedicals, LLC, Solon, $\mathrm{OH}$ ). The protocol was modified as follows: before analysis, the plasma samples were extracted, then reconstituted in zero standard. The assay sensitivity was $6.8 \mathrm{pg} / \mathrm{ml}$ 
and the intra- and interassay confidence intervals were 8.7 and $13.8 \%$, respectively. Plasma progesterone was determined in duplicate using a direct, double-antibody RIA kit (MP Biomedicals, LLC, Solon, Ohio). The assay sensitivity was $0.12 \mathrm{ng} / \mathrm{ml}$ and the intra- and interassay confidence intervals were 8.4 and $9.6 \%$, respectively.

\section{Data Analysis}

The primary dependent variable in this study was the progressive ratio break point, which was defined as the final completed ratio of responses for one cocaine injection. Progressive ratio break points were analyzed for 3 consecutive days at each of four phases of the menstrual cycle in females: (1) the early follicular phase, (2) the midfollicular phase, (3) the mid-luteal phase, and (4) the late luteal phase. In male pseudo-cycles, progressive ratio break points were analyzed for days $3-5,8-10,20-22$, and $28-30$ to correspond to four menstrual cycle phases in females. In ovulatory menstrual cycles, the first day of the cycle when samples were collected was defined as the estradiol and progesterone nadirs. Peak hormone levels usually occurred on different cycle days. Hormone levels and the corresponding progressive ratio break points are presented in a tabular form. Break points were compared via KruskalWallis ANOVA for non-parametric statistics with Dunn's multiple comparison test, or with the Mann-Whitney test for comparison of means. The criterion for significance was set at $P<0.05$. All analyses were conducted using commercially available software (GraphPad Prism, San Diego, CA).

\section{RESULTS}

\section{Menstrual Cycle Characteristics}

A total of 54 menstrual cycles were studied in female monkeys, and 44 of these cycles were ovulatory, as defined by mid-luteal phase elevations in progesterone, and 10 cycles were anovulatory. Peak progesterone levels during ovulatory cycles averaged $33.04 \pm 2.71 \mathrm{ng} / \mathrm{ml}$. Peak estradiol levels during ovulatory cycles averaged $229.58 \pm 16.75 \mathrm{pg} /$ $\mathrm{ml}$. The cocaine self-administration data presented below were analyzed separately for anovulatory and ovulatory cycles. In menstrual cycles that were classified as ovulatory, cocaine self-administration was compared during four phases of the cycle (early follicular, mid follicular, mid luteal, and late luteal). The average length of the ovulatory menstrual cycles was $30.1 \pm 1.7$ days, and the average length of the anovulatory cycles was $30.4 \pm 2.8$ days. In males, a total of 23 pseudo-cycles of 30 days duration were studied and compared with both ovulatory and anovulatory cycles in females.

Progressive ratio break points as a function of cocaine dose (Figure 1). Progressive ratio break points were cocaine dose-related. Figure 1 compares cocaine self-administration in males and females during ovulatory menstrual cycles, when a low $(0.0032 \mathrm{mg} / \mathrm{kg} / \mathrm{inj})$, moderate $(0.01 \mathrm{mg} / \mathrm{kg} / \mathrm{inj})$, and high $(0.032 \mathrm{mg} / \mathrm{kg} / \mathrm{inj})$ unit dose of cocaine was available. In females, during ovulatory menstrual cycles, progressive ratio break points were $94.9 \pm 5.2,172.8 \pm 9.8$, and $424.7 \pm 13.5$ at low, moderate, and high unit doses of
Sex Differences in Progressive Ratio Break Points for Cocaine

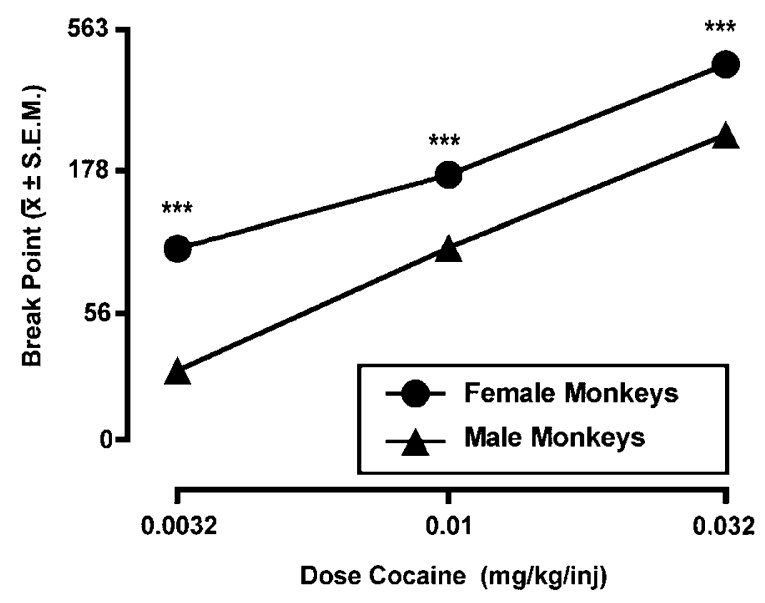

Figure I The effect of cocaine dose on progressive ratio break points for cynomolgus males and females. The unit dose of cocaine ( $\mathrm{mg} / \mathrm{kg} / \mathrm{inj})$ is shown on the abscissa (log scale). The break point, defined as the highest completed ratio for cocaine under a progressive ratio schedule, is shown on the left ordinate. All monkeys had unrestricted access to cocaine 7 days/ week. Closed circles indicate break points ( $\bar{x} \pm$ SEM) during ovulatory menstrual cycles for females $(N=4)$ and closed triangles indicate break points $(\bar{x} \pm$ SEM) during 30-day pseudo-cycles for males $(N=2)$. Each data point at the low, moderate, and high unit dose of cocaine is based on the average $(\bar{x} \pm$ SEM) of 10,11 , and 23 menstrual cycles in females and 7,3 , and 13 pseudo-cycles for males. Statistical analysis with the Kruskal-Wallis test for non-parametric statistics with Dunn's post-tests indicated a significant difference between males and females at each unit dose of cocaine as shown by the asterisks $(P<0.001)$.

cocaine, respectively. In males, progressive ratio break points were $35.1 \pm 2.6,95.7 \pm 6.8$, and $239.9 \pm 7.3$ at low, moderate, and high unit doses of cocaine, respectively. During ovulatory menstrual cycles, females reached significantly higher progressive ratio break points than males $(P<0.001)$ at all three unit doses of cocaine. Ovulatory females also self-administered significantly more cocaine $(\mathrm{mg} / \mathrm{kg})$ than males at all three doses of cocaine $(P<0.001)$. Anovulatory females also reached higher progressive ratio break points than males $(P<0.01)$, and self-administered significantly more cocaine than males at the highest unit dose of cocaine $(P<0.001)$.

During ovulatory cycles, females reached significantly higher progressive ratio break points than during anovulatory cycles $(P<0.001)$ and self-administered significantly more cocaine at moderate and high unit doses $(P<0.001)$. During anovulatory menstrual cycles, progressive ratio break points were $85.1 \pm 11.5$ at the moderate cocaine dose and $282.0 \pm 9.4$ at the high cocaine dose. There were no anovulatory cycles at the lowest dose of cocaine.

Progressive ratio break points as a function of the menstrual cycle phase (Figures 2 and 3). Figure 2 shows progressive ratio break points during four phases of ovulatory menstrual cycles at each of three unit doses of cocaine. At the lowest cocaine unit dose, average progressive ratio break points during the early and mid-follicular 


\section{Break Points in Ovulatory Menstrual Cycles}

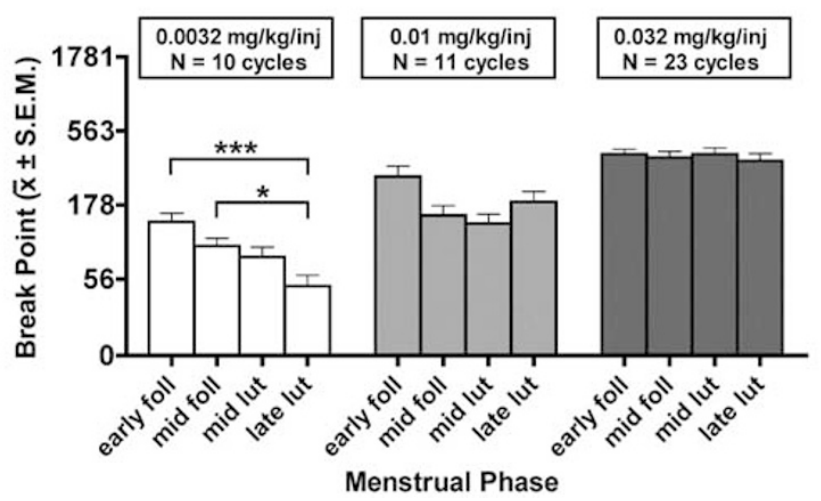

Figure 2 Progressive ratio break points and menstrual cycle phase during ovulatory menstrual cycles in cynomolgus females. Abscissae: phase of the menstrual cycle (early follicular, mid-follicular, mid-luteal, late luteal). Ordinate: progressive ratio break points (mean \pm SEM). The unit dose of cocaine available for self-administration $(0.0032,0.0 \mathrm{I}$, and $0.032 \mathrm{mg} / \mathrm{kg} / \mathrm{inj}$ ) is shown above each of the three average menstrual cycles. Each data point represents 3 days $(\bar{x}+S E M)$ at each of the four phases of the menstrual cycle. A total of 10,11 , and 23 ovulatory menstrual cycles averaging $30.1 \pm 1.7$ days duration were studied at the low, moderate, and high unit dose of cocaine. Statistical analysis (Kruskal-Wallis ANOVA for nonparametric data with Dunn's post-tests) indicated a significant main effect of menstrual cycle phase on the final ratio when the lowest dose of cocaine $(0.0032 \mathrm{mg} / \mathrm{kg} / \mathrm{inj})$ was available. The asterisks $\left(^{*}\right)$ indicate that the progressive ratio break points for $0.0032 \mathrm{mg} / \mathrm{kg} / \mathrm{inj}$ in the early and midfollicular phases were significantly higher than in the late luteal phase ( $* P<0.05$, **** $P<0.000$ I).

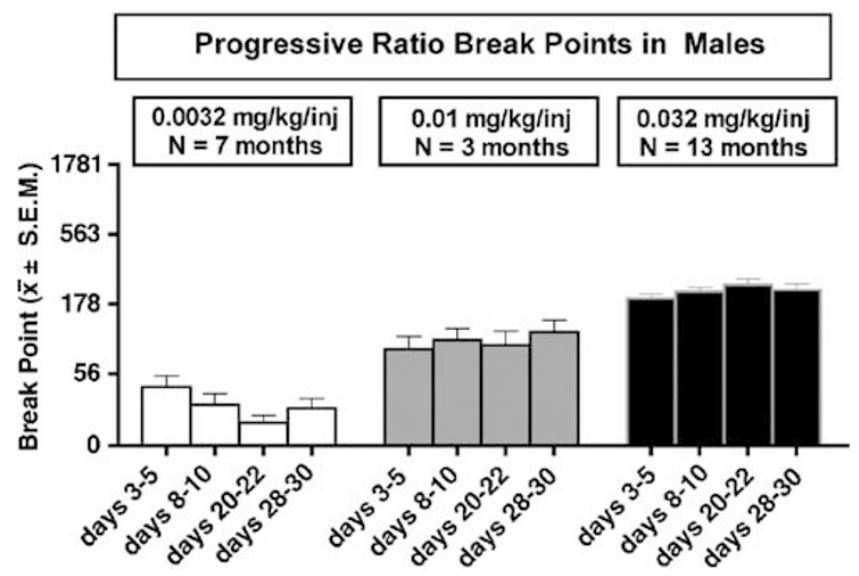

Figure 3 Progressive ratio break points during 30-day pseudo-cycles in cynomolgus male monkeys. Abscissae: each 3-day period (days 3-5, 8-10, 20-22, and 28-30) corresponded to each of the four menstrual cycle phases in ovulatory females shown in Figure 2. Progressive ratio break points (mean \pm SEM) are shown on the left ordinate. The unit dose of cocaine available for self-administration $(0.0032,0.0 \mathrm{I}$, and $0.032 \mathrm{mg} / \mathrm{kg} / \mathrm{inj})$ is shown above each of the three pseudo-cycles. Each data point represents an average of 7,3 , and 13 pseudo-cycles of 30 days duration in males at $0.0032,0.01$, and $0.032 \mathrm{mg} / \mathrm{kg} / \mathrm{inj}$ cocaine, respectively. KruskalWallis ANOVA for non-parametric data with Dunn's post-tests showed no significant effect of pseudo-cycle phases.

phase were significantly higher than during the late luteal phase $(P<0.05-0.01)$. Progressive ratio break points for the moderate and highest unit dose of cocaine did not differ significantly across phases of the menstrual cycle. Table 1 summarizes peak and nadir estradiol and progesterone levels and the corresponding progressive ratio break points at the low, moderate, and high unit dose of cocaine during ovulatory menstrual cycles. Progressive ratio break points on the day of peak levels of estradiol and peak levels of progesterone were consistently lower than on the hormone nadir days. These differences were significant only at the lowest unit dose of cocaine $(P<0.05)$. Table 2 shows the average estradiol and progesterone levels across anovulatory cycles at the moderate and high unit doses of cocaine. Average progesterone levels during anovulatory cycles did not differ significantly from the nadirs in Table 1 . However, average estradiol levels during anovulatory menstrual cycles were lower than the estradiol nadirs during ovulatory menstrual cycles, and these differences were significant at the highest unit dose of cocaine $(P<0.01)$.

Figure 3 shows progressive ratio break points in male pseudo-cycles for low, moderate, and high doses of cocaine. There were no significant differences across phases of the male pseudo-cycles at any unit dose of cocaine. Both ovulatory and anovulatory females had significantly higher progressive ratio break points than males in the early and mid-follicular phases of the cycle at $0.032 \mathrm{mg} / \mathrm{kg} / \mathrm{inj}$ cocaine $(P<0.005, P<0.05)$.

Progressive ratio performance in individual monkeys (Figure 4). Figure 4 shows typical patterns of progressive ratio performance across a single ovulatory menstrual cycle in individual monkeys. Ovulation is inferred from the midluteal phase elevations in progesterone. Monkeys maintained higher progressive ratio break points at the highest dose of cocaine $(0.032 \mathrm{mg} / \mathrm{kg} / \mathrm{inj})$ than at the low and moderate doses of cocaine. Although there was considerable variability in progressive ratio break points, especially at the lowest unit dose of cocaine, examination of daily break points did not reveal consistent patterns as a function of menstrual cycle phase.

\section{DISCUSSION}

One major finding of this study was that during ovulatory menstrual cycles, females self-administered significantly more cocaine and reached higher progressive ratio break points than males. A significant sex difference in cocainemaintained responding was observed at low, moderate, and high unit doses of cocaine. During anovulatory cycles, females also reached higher progressive ratio break points for a high unit dose of cocaine than males. As noted earlier, there has been considerable inconsistency between studies of sex differences in behavioral responses to cocaine. Female rodents often self-administer more cocaine than males, and our findings in cynomolgus monkeys are consistent with some (Roberts et al, 1989; Hu et al, 2004; Lynch and Taylor, 2004) but not all previous studies in rats (Caine et al, 2004). Some clinical studies have shown that men have greater positive subjective responses to cocaine (Haney et al, 1998; Sofuoglu et al, 1999) and to amphetamine than women (Munro et al, 2006). Another study found that men had greater subjective responses to $d$-amphetamine than luteal phase women, but did not differ significantly from follicular-phase women (White et al, 
Table I Progressive Ratio Break Points at Peak Levels and Nadirs of Ovarian Steroid Hormones During Ovulatory Menstrual Cycles

Hormone level nadirs

Peak hormone levels

\begin{tabular}{|c|c|c|c|c|c|c|c|}
\hline $\begin{array}{l}\text { Cocaine dose } \\
\text { (mg/kg/inj) }\end{array}$ & $\begin{array}{c}\text { Estradiol } \\
(\mathrm{pg} / \mathrm{ml})\end{array}$ & $\begin{array}{c}\text { Progesterone } \\
(\mathrm{ng} / \mathrm{ml})\end{array}$ & $\begin{array}{l}\text { Break } \\
\text { Point }\end{array}$ & $\begin{array}{c}\text { Estradiol } \\
(\mathrm{pg} / \mathrm{ml})\end{array}$ & $\begin{array}{l}\text { Break } \\
\text { point }\end{array}$ & $\begin{array}{l}\text { Progesterone } \\
(\mathrm{ng} / \mathrm{ml})\end{array}$ & $\begin{array}{l}\text { Break } \\
\text { point }\end{array}$ \\
\hline 0.0032 & $78.3 \pm 15.0$ & $1.51 \pm 0.35$ & $205.3 \pm 40.4$ & $269.7 \pm 56.4$ & $145.5 \pm 39.9$ & $35.9 \pm 6.8$ & $98.0 \pm 52.8$ \\
\hline 0.032 & $83.1 \pm 7.9$ & $1.3 \pm 0.19$ & $445.9 \pm 98.7$ & $260.3 \pm 21.7$ & $419.1 \pm 110.4$ & $35.8 \pm 4.2$ & $391.6 \pm 66.4$ \\
\hline
\end{tabular}

Table 2 Mean Levels of Ovarian Steroid Hormones and Progressive Ratio Break Points During Anovulatory Menstrual Cycles

\begin{tabular}{lccc}
\hline $\begin{array}{l}\text { Cocaine dose } \\
(\mathbf{m g} / \mathbf{k g} / \mathbf{i n j})\end{array}$ & $\begin{array}{c}\text { Estradiol } \\
\mathbf{( p g / m l )}\end{array}$ & $\begin{array}{c}\text { Progesterone } \\
\mathbf{( n g / m l )}\end{array}$ & $\begin{array}{c}\text { Break } \\
\text { point }\end{array}$ \\
\hline 0.01 & $53.27 \pm 9.35$ & $1.36 \pm 0.22$ & $109.5 \pm 88.5$ \\
0.032 & $43.67 \pm 18.49$ & $1.30 \pm 0.19$ & $314.8 \pm 35.7$ \\
\hline
\end{tabular}

2002). Minimal or no sex differences in subjective responses to cocaine have also been reported (Kosten et al, 1996; Evans et al, 1999; Mendelson et al, 1999b). In one clinical study, men worked more for i.v. cocaine than women on a progressive ratio schedule and rated 'stimulated' and cocaine 'dose quality' higher than women (Haney et al, 1998). Although progressive ratio break points for cocaine cannot be directly equated with positive subjective responses on questionnaire measures, both reflect the abuse-related properties of drugs.

It is reasonable to assume that sex differences in cocainemaintained responding in cynomolgus monkeys are related to differences in the hormonal milieu because all experimental conditions were identical for males and females. This conclusion is supported by the finding that during anovulatory cycles, females also reached higher progressive ratio break points than males. Although it is possible that sex differences in cocaine's pharmacokinetics could account for these findings, this seems unlikely. It is well established that there are no sex differences in cocaine's pharmacokinetics in rodents, non-human primates, and humans. In rats, no differences between males and females were detected, and gonadectomy did not significantly alter cocaine's pharmacokinetics (Bowman et al, 1999). Rhesus monkeys also did not show sex differences in cocaine's pharmacokinetics (Mendelson et al, 1999a; Evans and Foltin, 2004; Mello et al, 2004). In clinical studies, no significant sex or menstrual cycle phase differences in cocaine's pharmacokinetics were detected in men and women studied at the follicular and mid-luteal phases of the menstrual cycle (Mendelson et al, 1999b).

A second major finding of this study was that variations in ovarian steroid hormone levels across phases of the menstrual cycle did not influence progressive ratio break points for cocaine at unit doses that maintained stable responding. Cocaine unit doses of 0.01 and $0.032 \mathrm{mg} / \mathrm{kg} / \mathrm{inj}$ were on the ascending limb of the dose-effect curve, whereas $0.0032 \mathrm{mg} / \mathrm{kg} / \mathrm{inj}$ did not maintain responding significantly above saline levels in our previous progressive ratio study (Negus and Mello, 2003). The availability of low, moderate, and high unit doses of cocaine resulted in doserelated changes in progressive ratio break points, but there was no consistent variation in cocaine self-administration as a function of phases of the menstrual cycle. These data cannot be attributed to abnormalities of the menstrual cycle because only ovulatory menstrual cycles were analyzed for cycle phase effects, and ovulation was confirmed by luteal phase elevations in progesterone. Although cocaine can produce profound disruptions of the menstrual cycle, including anovulation, amenorrhea, and luteal phase defects in rhesus monkeys, these abnormalities occurred after relatively high daily doses of cocaine $(4-7 \mathrm{mg} / \mathrm{kg}$ ) (Mello et al, 1997; Chen et al, 1998; Potter et al, 1998). In the present study, at the highest unit dose of cocaine $(0.032 \mathrm{mg} /$ $\mathrm{kg} / \mathrm{inj}$ ), monkeys self-administered an average of only $1.31 \mathrm{mg} / \mathrm{kg} /$ day.

The proportion of anovulatory cycles in the present study was similar to that observed in the same monkeys during 10 months of food self-administration with no access to cocaine (Roth et al, 2005). In that study, progressive ratio break points for $1 \mathrm{~g}$ banana pellets $(3.2 \mathrm{kcal} / \mathrm{pellet})$ also did not vary as a function of menstrual cycle phase during 21 ovulatory menstrual cycles (Roth et al, 2005). Males reached significantly higher progressive ratio break points for food than females, even though they were fed more biscuits ( $60.5 \mathrm{kcal} / \mathrm{biscuit})$ each day than females. These differences in food-maintained responding were interpreted as reflecting the fact that males were larger than females (Roth et al, 2005).

The lack of menstrual cycle phase-dependent changes in cocaine self-administration in cynomolgus monkeys is not consistent with a number of reports that cocaine selfadministration by rodents is enhanced at the proestrus and estrus phase of the estrous cycle (see for review Lynch et al, 2002; Mello and Mendelson, 2002; Carroll et al, 2004). Beyond the obvious differences in species, and the hormonal characteristics and duration of the estrous cycle (4-5 days) and the menstrual cycle (28-30 days), there are also several procedural differences that may have contributed to these discrepant findings.

Study duration. In most studies in rodents, cocaine selfadministration was studied for about 2 weeks (ie, 1-3 estrous cycles), whereas in the present study, 44 ovulatory menstrual cycles and 10 anovulatory menstrual cycles were analyzed. Repeated measures of the association between menstrual cycle phase and progressive ratio break points increase confidence in the robustness of these findings. 
Cocaine $0.0032 \mathrm{mg} / \mathrm{kg} / \mathrm{inj}$

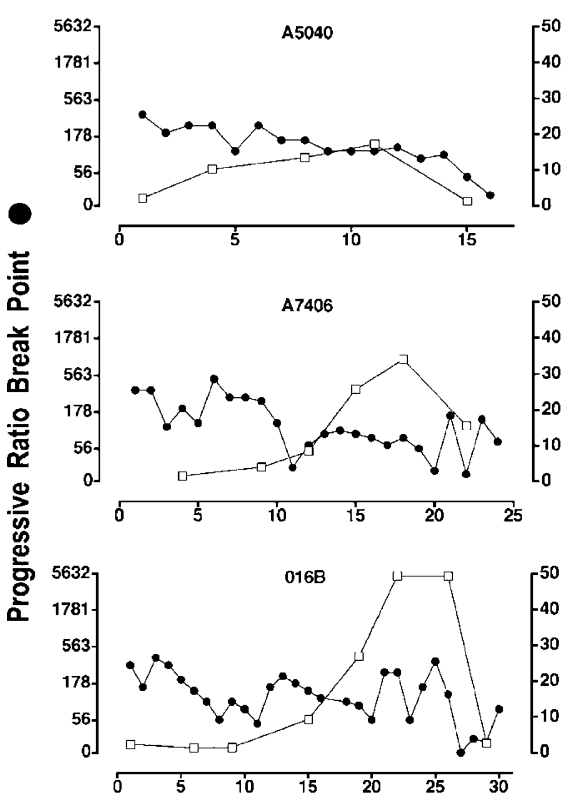

Cocaine $0.01 \mathrm{mg} / \mathrm{kg} / \mathrm{inj}$
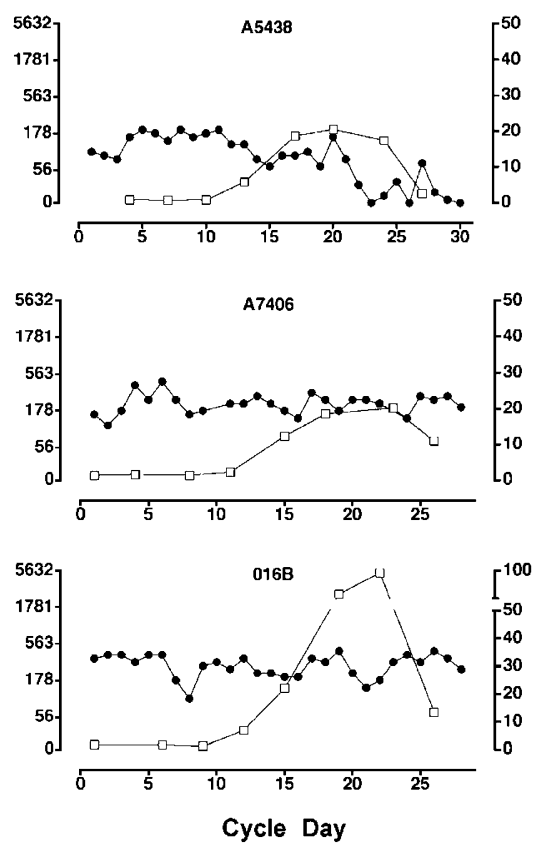

Cocaine $0.032 \mathrm{mg} / \mathrm{kg} / \mathrm{inj}$
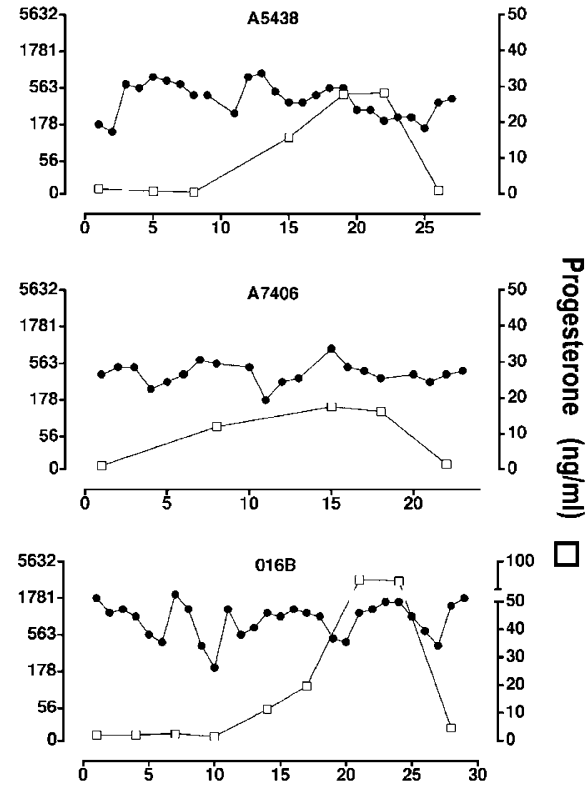

Figure 4 Progressive ratio break points and progesterone levels during a single ovulatory menstrual cycle in individual female cynomolgus monkeys. Abscissae: cycle length (days) during each ovulatory menstrual cycle. Ordinates: progressive ratio break points are shown on the left ordinates and displayed as filled circles for each day of the menstrual cycle. Progesterone levels $(\mathrm{ng} / \mathrm{ml})$ are shown on the right ordinates and displayed as open squares on the sample collection day. The dose of cocaine available for self-administration $(0.0032,0.01$, and $0.032 \mathrm{mg} / \mathrm{kg} / \mathrm{inj})$ is shown above each column.

Moreover, this longitudinal study provided an opportunity to determine if cocaine-maintained responding remained stable over time. There were no consistent changes in cocaine-maintained responding as a function of months of cocaine exposure.

Cocaine unit dose available for self-administration. Usually a single unit dose of cocaine was studied in rodents whereas in the present study three doses of cocaine were examined. As noted earlier, it is often argued that low unit doses of cocaine are necessary to reveal the effects of estrous cycle phase and sex on cocaine self-administration (Lynch et al, 2002; Carroll et al, 2004). Consistent with this notion, significant menstrual cycle phase differences in cocaine selfadministration by cynomolgus monkeys were detected only at the lowest unit dose of cocaine studied. That low unit dose of cocaine did not maintain consistent cocaine selfadministration in most monkeys. However, at unit doses that maintained stable cocaine self-administration in all monkeys, there was no evidence of menstrual cycle phase effects. These data are consistent with some previous studies in rodents when self-administration of behaviorally effective doses of cocaine was maintained on an FR 1 or FR 5 schedule of reinforcement (Roberts et al, 1989; Caine et al, 2004).

Operant training before drug self-administration. Many studies have examined acquisition of cocaine self-administration in rodents with no prior operant training. In the present study, cynomolgus monkeys were trained to selfadminister banana-flavored food pellets on the same progressive ratio schedule used for cocaine self-administration (Roth et al, 2005). Although operant training for food reinforcement facilitates the transition to drugmaintained responding (Caine et al, 2004), it is unlikely that this experience obscured menstrual cycle phase effects on cocaine self-administration. In the first report that progressive ratio break points for cocaine were higher at estrus, rats were trained to self-administer food before cocaine exposure (Roberts et al, 1989).

Hormonal verification of menstrual cycle phase and ovulation. An important strength of the present study was that ovulation was confirmed by mid-luteal phase elevations in progesterone assessed by radioimmunoassay. Many previous studies have not verified estrous/menstrual cycle phase with hormonal measures, and have not determined whether or not ovulation occurred. The observed differences in cocaine self-administration during ovulatory and anovulatory cycles suggest that ovulation may be important to consider as one biological modulator of cocaine self-administration.

The contribution of ovarian steroid hormones to the abuse-related effects of cocaine remains unresolved, and as described earlier, there are many inconsistencies in the clinical and preclinical literature. In the present study, progressive ratio break points for cocaine did not differ 
significantly in females when estradiol levels were low (below $100 \mathrm{pg} / \mathrm{ml}$ ) or high (near or above $200 \mathrm{pg} / \mathrm{ml}$ ). These data are consistent with clinical studies that compared subjective responses to $d$-amphetamine during the early and late follicular phase (Justice and de Wit, 2000a) and examined the effects of estradiol administration to follicular phase women (Justice and de Wit, 2000b). Interestingly, estradiol levels of $750 \mathrm{pg} / \mathrm{ml}$ (about 10-fold higher than normal early follicular phase levels) did not increase ratings of 'High,' 'Euphoria,' and 'Like drug' after $d$-amphetamine in comparison to placebo (Justice and de Wit, 2000b). High progesterone levels during the mid-luteal phase also did not affect progressive ratio break points at moderate and high doses of cocaine that maintained stable self-administration in cynomolgus monkeys. This is not consistent with clinical studies in which high progesterone levels during the luteal phase of the menstrual cycle and administration of physiological levels of progesterone each were associated with lower ratings of positive subjective responses to cocaine than during the follicular phase when progesterone levels were low (Evans et al, 2002; Sofuoglu et al, 2002, 2004; Evans and Foltin, 2006). This is also inconsistent with a report that progesterone prevented estradiol-induced enhancement of cocaine acquisition in ovariectomized rats (Jackson et al, 2006).

One limitation of the present study is that cynomolgus monkeys were not given exogenous estradiol or progesterone. Rather the influence of these hormones on cocaine self-administration was inferred from physiological levels of ovarian steroid hormones across the menstrual cycle. The menstrual cycles of cynomolgus females are very similar to those of women, and this chronic cocaine self-administration model seemed most analogous to women who are cocaine abusers. In women, as in cynomolgus females, it is likely that the dose of cocaine available for self-administration is a more important determinant of behavior than fluctuations in ovarian steroid hormones across the menstrual cycle. However, the significant dose-dependent differences in cocaine self-administration between males and females during both ovulatory and anovulatory menstrual cycles is intriguing and suggests that sex differences in neurobiological substrates may modulate the reinforcing properties of cocaine.

This issue has been examined in a comparison of cocaine self-administration by gonadectomized male and female rats (Hu et al, 2004). Ovariectomized rats, with and without estradiol treatment, self-administered equivalent amounts of $0.5 \mathrm{mg} / \mathrm{kg} / \mathrm{inj}$ cocaine and took significantly more cocaine than male rats (Hu et al, 2004). These data were interpreted as reflecting intrinsic sex differences in brain organization that may influence responses to cocaine, independent of circulating levels of estradiol ( $\mathrm{Hu}$ et al, 2004). Evidence consistent with this argument comes from a recent positron emission tomography (PET) study of striatal dopamine release in response to $d$-amphetamine in men and women (Munro et al, 2006). Dopamine release was greater in men than in women, and there were no differences in dopamine release between women studied during the follicular and the luteal phase of the menstrual cycle (Munro et al, 2006). Ratings of positive subjective responses to $d$-amphetamine were also higher in men than in women, but did not differ in women as a function of menstrual cycle phase (Munro et al,
2006). The lack of menstrual cycle phase differences in dopamine release and subjective responses to $d$-amphetamine is consistent with our findings in female cynomolgus monkeys; ie, at reinforcing doses of cocaine, progressive ratio break points did not differ significantly across phases of the menstrual cycle. However, the implications of these PET data for predicting the direction of sex differences in response to stimulant drugs are less obvious. Although it is possible that greater striatal dopamine release in men could enhance the vulnerability to addiction in comparison to women, as suggested by Munro et al (2006), an alternative hypothesis is that women might take more $d$-amphetamine to achieve a salient subjective effect. A clearer understanding of the neurobiology of sex differences, and how these differences may influence the initiation and perpetuation of drug addiction is important and may facilitate improved approaches to treatment and prevention.

\section{ACKNOWLEDGEMENTS}

We thank Kevin Costa, Peter Fivel, Maureen Kelly, Melissa Timm, and Kyle Rheaume for their technical assistance. This research was supported in part by Grants R01 DA14670, K05 DA00101, and K05 DA00064 from the National Institute on Drug Abuse, NIH. Preliminary data were presented at the 68th Annual Meeting of the College on Problems of Drug Dependence in 2006.

\section{REFERENCES}

Appt SE (2004). Usefulness of the monkey model to investigate the role of soy in postmenopausal women's health. Ilar J 45: 200-211.

Arnold JM, Roberts DCS (1997). A critique of fixed and progressive ratio schedules used to examine the neural substrates of drug reinforcement. Pharmacol Biochem Behav 57: 441-447.

Barbier O, Belanger A (2003). The cynomolgus monkey (Macaca fascicularis) is the best animal model for the study of steroid glucuronidation. J Steroid Biochem Mol Biol 85: 235-245.

Becker JB (1999). Gender differences in dopaminergic function in striatum and nucleus accumbens. Pharmacol Biochem Behav 64: 803-812.

Becker JB, Molenda H, Hummer DL (2001). Gender differences in the behavioral responses to cocaine and amphetamine. Implications for mechanisms mediating gender differences in drug abuse. Ann NY Acad Sci 937: 172-187.

Bowman BP, Vaughan SR, Walkler QD, Davis SL, Little PJ, Scheffler NM et al (1999). Effects of sex and gonadectomy of cocaine metabolism in the rat. J Pharmacol Exp Ther 290: $1316-1323$.

Brebner K, Phelan R, Roberts DCS (2000). Effect of baclofen on cocaine self-administration in rats reinforced under fixed ratio-1 and progressive ratio schedules. Psychopharmacology 148: 314-321.

Caine SB, Bowen CA, Yu G, Zuzga D, Negus SS, Mello NK (2004). Effect of gonadectomy and gonadal hormone replacement on cocaine self-administration in female and male rats. Neuropsychopharmacology 29: 929-942.

Carroll ME, Lynch WJ, Roth ME, Morgan AD, Cosgrove KP (2004). Sex and estrogen influence drug abuse. Trends Pharmacol Sci 25 273-279.

Channing CP, Fowler S, Engel B, Vitek K (1977). Failure of daily injections of ketamine $\mathrm{Hcl}$ to adversely alter menstrual cycle length, blood estrogen and progesterone levels in the rhesus monkey. Proc Soc Exp Biol Med 155: 615-619. 
Chen EC, Samuels MH, Luther MF, King TS, Eddy CA, Siler-Khodr TM et al (1998). Cocaine impairs follicular phase pulsatile gonadotropin secretion in rhesus monkeys. J Soc Gynecol Investig 5: 311-316.

Clark UH, Mani SK (1994). Actions of ovarian steroid hormones. In: Knobil E, Neill JD (eds). The Physiology of Reproduction, 2nd edn. Raven Press, Ltd: New York. pp 1011-1059.

Dierschke DJ, Yamaji T, Karsch FJ, Weick RF, Weiss G, Knobil E (1973). Blockade by progesterone of estrogen-induced LH and FSH release in the rhesus monkey. Endocrinology 92: 1496-1501.

Evans SM, Foltin RW (2004). Pharmacokinetics of intravenous cocaine across the menstrual cycle in rhesus monkeys. Neuropsychopharmacology 29: 1889-1900.

Evans SM, Foltin RW (2006). Exogenous progesterone attenuates the subjective effects of smoked cocaine in women, but not in men. Neuropsychopharmacology 31: 659-674.

Evans SM, Haney M, Fischman MW, Foltin RW (1999). Limited sex differences in response to 'binge' smoked cocaine use in humans. Neuropsychopharmacology 21: 445-454.

Evans SM, Haney M, Foltin RW (2002). The effects of smoked cocaine during the follicular and luteal phases of the menstrual cycle in women. Psychopharmacology 159: 397-406.

Festa ED, Quinones-Jenab V (2004). Gonadal hormones provide the biological basis for sex differences in behavioral responses to cocaine. Horm Behav 46: 509-519.

Goodman AL, Hodgen GD (1983). The ovarian triad of the primate menstrual cycle. Rec Prog Horm Res 39: 1-67.

Grimm JW, See RE (1996). Cocaine self-administration in ovariectomized rats is predicted by response to novelty, attenuated by $17-\beta$ estradiol, and associated with abnormal vaginal cytology. Physiol Behav 61: 755-761.

Haney M, Foltin RW, Fischman M (1998). Effects of pergolide on intravenous cocaine self-administration in men and women. Psychopharmacology 137: 15-24.

Hecht GS, Spear NE, Spear LP (1999). Changes in progressive ratio responding for intravenous cocaine throughout the reproductive process in female rats. Dev Psychobiol 35: 136-145.

Hemby SE, Co C, Koves TR, Smith JE, Dworkin SI (1997). Differences in extracelluar dopamine concentrations in the nucleus accumbens during response-dependent and responseindependent cocaine administration in the rat. Psychopharmacology 133: 7-16.

Hodgen GD (1982). The dominant ovarian follicle. Fertil Steril 38: 281-300.

Hu M, Crombag HS, Robinson TE, Becker JB (2004). Biological basis of sex differences in the propensity to self-administer cocaine. Neuropsychopharmacology 29: 81-85.

Jackson LR, Robinson TE, Becker JB (2006). Sex differences and hormonal influences on acquisition of cocaine self-administration in rats. Neuropsychopharmacology 31: 129-138.

Justice AJ, de Wit H (2000a). Acute effects of $d$-amphetamine during the early and late follicular phases of the menstrual cycle in women. Pharmacol Biochem Behav 66: 509-515.

Justice AJ, de Wit H (2000b). Acute effects of estradiol pretreatment on the response to $d$-amphetamine in women. Neuroendocrinology 71: 51-59.

Justice AJH, de Wit H (1999). Acute effects of $d$-amphetamine during the follicular and luteal phases of the menstrual cycle in women. Psychopharmacology 145: 67-75.

Katz JL (1990). Models of relative reinforcing efficacy and their predictive utility. Behav Pharmacol 1: 283-301.

Kosten TR, Kosten TA, McDougle CJ, Hameedi FA, McCance EF, Rosen MI et al (1996). Gender differences in response to intranasal cocaine administration to humans. Biol Psychiatry 39: 147-148.

Kuhar MJ, Ritz MC, Boja JW (1991). The dopamine hypothesis of the reinforcing properties of cocaine. TINS 14: 299-302.
Lukas SE, Sholar M, Lundahl LH, Lamas X, Kouri E, Wines JD et al (1996). Sex differences in plasma cocaine levels and subjective effects after acute cocaine administration in human volunteers. Psychopharmacology 125: 346-354.

Lynch WJ, Arizzi MN, Carroll ME (2000). Effects of sex and the estrous cycle on regulation of intravenously self-administered cocaine in rats. Psychopharmacology 152: 132-139.

Lynch WJ, Roth ME, Carroll ME (2002). Biological basis of sex differences in drug abuse: preclinical and clinical studies. Psychopharmacology 164: 121-137.

Lynch WJ, Roth ME, Mickelberg JL, Carroll ME (2001). Role of estrogen in the acquisition of intravenously self-administered cocaine in female rats. Pharmacol Biochem Behav 68: 641-646.

Lynch WJ, Taylor JR (2004). Sex differences in the behavioral effects of 24-h/day access to cocaine under a discrete trial procedure. Neuropsychopharmacology 29: 943-951.

Lynch WJ, Taylor JR (2005). Decreased motivation following cocaine self-administration under extended access conditions: effects of sex and ovarian hormones. Neuropsychopharmacology 30: 927-935.

Mello NK, Mendelson JH (1997). Cocaine's effects on neuroendocrine systems: clinical and preclinical studies. Special issue on current issues in psychostimulant abuse research. Special Issue on Current Issues in Psychostimulant Abuse Research Pharmacol Biochem Behav 57: 571-599.

Mello NK, Mendelson JH (2002). Cocaine, hormones and behavior. In: Pfaff DW, Arnold AP, Etgen AM, Fahrbach SE, Rubin RT (eds). Hormones, Brain and Behavior. Academic Press: San Diego, CA. pp 665-745.

Mello NK, Mendelson JH, Kelly M, Bowen CA (2000). The effects of cocaine on basal and human chorionic gonadotropinstimulated ovarian steroid hormones in female rhesus monkeys. J Pharmacol Exp Ther 294: 1137-1145.

Mello NK, Mendelson JH, Kelly M, Diaz-Migoyo N, Sholar JW (1997). The effects of chronic cocaine self-administration on the menstrual cycle in rhesus monkeys. J Pharmacol Exp Ther 281: $70-83$.

Mello NK, Mendelson JH, Negus SS, Kelly M, Knudson I, Roth ME (2004). The effects of cocaine on gonadal steroid hormones and LH in male and female rhesus monkeys. Neuropsychopharmacology 29: 2024-2034.

Mendelson JH, Mello NK, Negus SS (1999a). Effects of luteinizinghormone-releasing-hormone on plasma cocaine levels in rhesus monkeys. J Pharmacol Exp Ther 289: 791-799.

Mendelson JH, Mello NK, Sholar MB, Siegel AJ, Kaufman MJ, Levin JM et al (1999b). Cocaine pharmacokinetics in men and in women during the follicular and luteal phase of the menstrual cycle. Neuropsychopharmacology 21: 294-303.

Munro CA, McCaul ME, Wong DF, Oswald LM, Zhou Y, Brasic J et al (2006). Sex differences in striatal dopamine release in healthy adults. Biol Psychiatry 59: 966-974.

Negus SS, Mello NK (2003). Effects of chronic $d$-amphetamine treatment on cocaine- and food-maintained responding under a progressive-ratio schedule in rhesus monkeys. Psychopharmacology 167: 324-332.

NIDA (1998). Epidemiologic Trends in Drug Abuse. National Institute on Drug Abuse, NIH: Washington, DC.

ONDCP (1998). National Drug Control Strategy: 1998. Office of National Drug Control Policy, Executive Office of the President, 1999. 138pp.

Potter DA, Moreno A, Luther MF, Eddy CA, Siler-Khodr TM, King TS et al (1998). Effects of follicular-phase cocaine administration on menstrual and ovarian cyclicity in rhesus monkeys. Am J Obstet Gynecol 178: 118-125.

Roberts DCS, Andrews MM, Vickers GJ (1996). Baclofen attenuates the reinforcing effects of cocaine in rats. Neuropsychopharmacology 15: 417-423. 
Roberts DSC, Bennett SA, Vickers GJ (1989). The estrous cycle affects cocaine self-administration on a progressive ratio schedule in rats. Psychopharmacology 98: 408-411.

Roth ME, Carroll ME (2004). Sex differences in the escalation of intravenous cocaine intake following long- or short-access to cocaine self-administration. Pharmacol Biochem Behav 78: 199-207.

Roth ME, Negus SS, Knudson IM, Burgess MP, Mello NK (2005). Effects of gender and menstrual cycle phase on food-maintained responding under a progressive-ratio schedule in cynomolgus monkeys. Pharmacol Biochem Behav 82: 735-743.

Rothman RB, Glowa JR (1995). A review of the effects of dopaminergic agents on humans, animals, and drug-seeking behavior, and its implications for medication development: Focus on GBR 12909. Mol Neurobiol 10: 1-19.

Sofuoglu M, Babb DA, Hatsukami DK (2002). Effects of progesterone treatment on smoked cocaine response in women. Pharmacol Biochem Behav 72: 431-435.

Sofuoglu M, Dudish-Poulsen S, Nelson D, Pentel PR, Hatsukami DK (1999). Sex and menstrual cycle differences in the subjective effects from smoked cocaine in humans. Exp Clin Psychopharmacol 7: 274-283.
Sofuoglu M, Mitchell E, Kosten TR (2004). Effects of progesterone treatment on cocaine responses in male and female cocaine users. Pharmacol Biochem Behav 78: 699-705.

Stafford D, Branch MN (1998). Effects of step size and break-point criterion on progressive-ratio performance. J Exp Anal Behav 70: 123-128.

Terner JM, de Wit H (2006). Menstrual cycle phase and responses to drugs of abuse in humans. Drug Alcohol Depend 84: 1-13.

Van Vugt DA, Heisler LE, Reid RL (1992). Progesterone inhibits the estrogen-induced gonadotropin surge in the rhesus monkey independent of endogenous opiates. J Clin Endocrinol Metab 74: 1312-1319.

White TL, Justice AJ, de Wit H (2002). Differential subjective effects of $d$-amphetamine by gender, hormone levels and menstrual cycle pahse. Pharmacol Biochem Behav 73: 729-741.

Wildt L, Hutchison JS, Marshall G, Pohl CR, Knobil E (1981). On the site of action of progesterone in the blockade of the estradiol-induced gonadotropin discharge in the rhesus monkey. Endocrinology 109: 1293-1294.

Woolverton WL, Johnson KM (1992). Neurobiology of cocaine abuse. Trends Pharmacol Sci 13: 193-200. 